\title{
Hur påverkas fågelfaunan av upphörd betesdrift - data från en 26 år lång inventeringsstudie
}

\author{
How does a bird community change as a consequence of ceased cattle grazing- \\ data from a 26 year long census study
}

THOMAS CARLSSON

The breeding bird fauna of a $1.6 \mathrm{~km}^{2}$ large grassland area
in southwestern Sweden was monitored in $1987-2012$,
using the point count method. The area was grazed by
approximately 500 cattle until 2006 , and the grass height
was then at most $10-15 \mathrm{~cm}$ except for higher tussocks.
From 2007 onwards, when the grazing had ceased, the
grass increased in height to $20-30 \mathrm{~cm}$ and became much
thicker. The average number of bird species per year
was 44.7 over the 26 year survey period. Numbers of
some farmland birds such as Lapwing Vanellus vanellus,
Skylark Alauda arvensis, Starling Sturnus vulgaris, and
Linnet Carduelis cannabina decreased in the study area,

following the general pattern in the whole of Sweden. Meadow Pipit Anthus pratensis, Corn Crake Crex crex, Whinchat Saxicola rubetra and Grasshopper Warbler Locustella naevia increased in the area, but decreased in Sweden in general over the same period. The local changes in bird numbers in the study area seem mainly to be caused by an increased grass height and thickness as a consequence of ceased cattle grazing.

Thomas Karlsson, Brunnsbacken 7, 47550 Hälsö, Sweden.Email: tk.golfbird@telia.com

Received 20 May 2013, Accepted 26 November 2013, Editor D. Hasselquist

\section{Inledning}

Sedan 1987 har jag genomfört punktinventeringar av häckande fåglar på ett militärt område utanför Skövde, Västergötland, enligt den punktruttsmetod som används inom den nationella fågelövervakningen (Lindström m.fl. 2012). De öppna områdena i undersökningsytan har huvudsakligen bestått av betesmarker. Ytan har, så vitt jag kunnat utröna, inte genomgått några dramatiska förändringar $\mathrm{i}$ markanvändning förutom på en punkt. Från 2007 upphörde betesdriften i området. Stora delar av området hade fram till dess betats av cirka 500 kor under perioden maj-november. Därutöver har marken använts för militära övningar.

I Sverige har många arter knutna till jordbruksmarker minskat kraftigt $\mathrm{i}$ antal under de senaste årtiondena. Minskningen är knuten till någon form av förändringar i jordbruket (Lindström m.fl. 2012, Ottosson m.fl. 2012). Jordbruket har sedan 1970-talet genomgått olika intensiva skeenden. En period med kraftig intensifiering av jordbruket skedde under 1970-talet fram till 1987. Denna följdes av en period, 1987-1995, där mycket jordbruksmark lades i träda och en hel del jordbruk i skogsområden till och med försvann. Från 1995, med Sveriges inträde i EU, skedde en ökad användning av bekämpningsmedel. Dessutom har landskapets utformning och jordbruksmarkens närhet till skog betydelse för fåglar i jordbrukslandskapet (Wretenberg 2006).

Med den bakgrunden i åtanke var huvudfrågan här hur fågelfaunan har förändrats i ett område med gräsmark där betesdriften upphört. Här jämför jag förekomsten av jordbruksfåglar, och vissa andra arter, under perioden när området betades med perioden efter att betesdriften hade upphört.

\section{Metodik}

Fältarbetet utfördes med samma punkttaxeringsmetod som används inom den nationella fågelövervakningen (Lindström m.fl. 2012). Metoden innebär att man på var och en av 20 punkter stannar i 5 minuter och räknar alla fåglar som observeras, oavsett avstånd från observatören. Avståndet mellan varje punkt var $600-4000 \mathrm{~m}$. Jag har utfört fågelräkningarna i mitt studieområde runt 1 maj 1987-2012 (maj-inventeringen), 1 juni 1987-1994 och 2008-2012 (juni-inventeringen) samt 1 juli 1989-1995 och 2008-2012 (juli-inventeringen). 


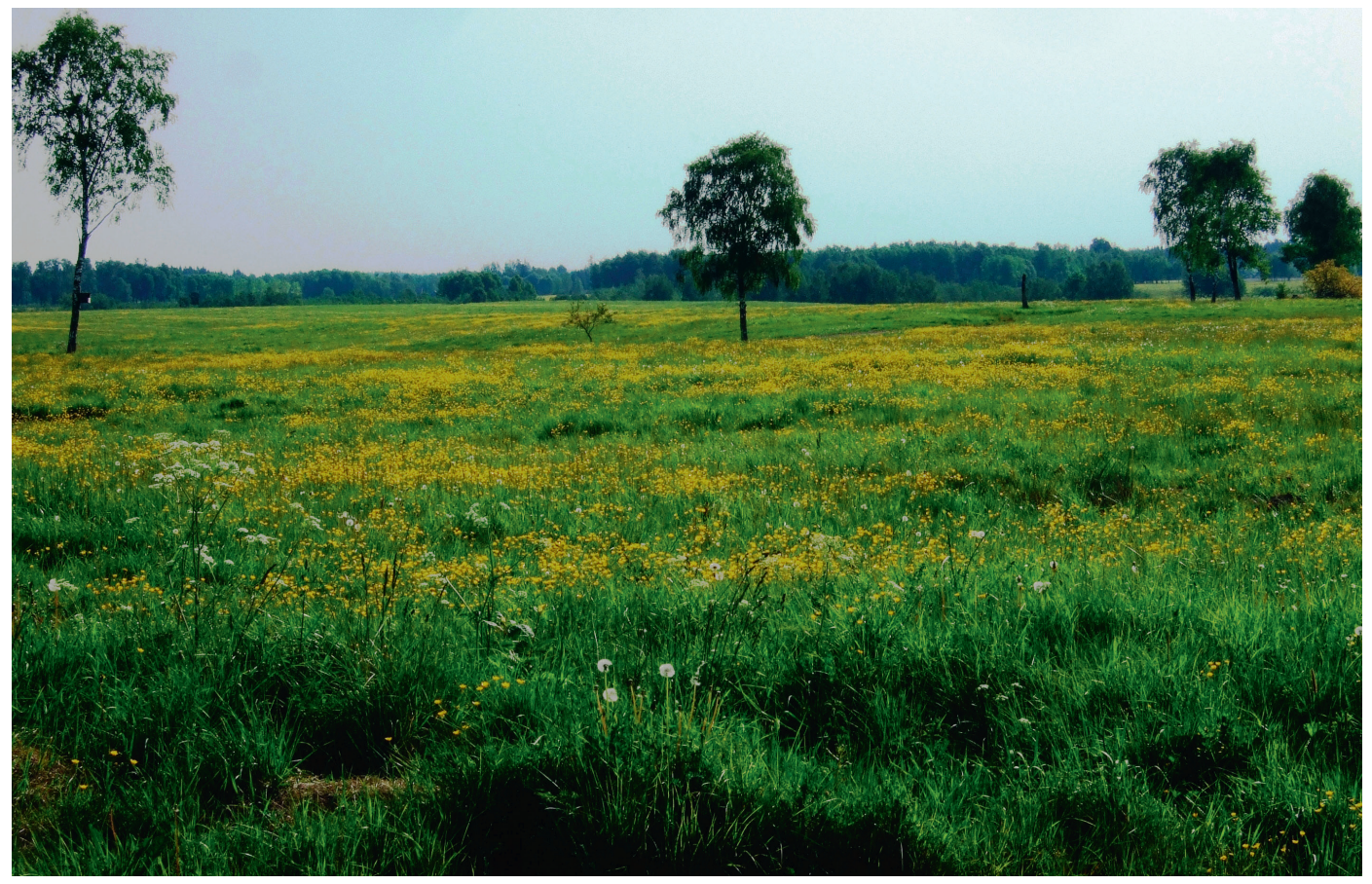

Figur 1. Del av undersökningsområdet. Efter att betesdriften upphört blir vegetationen hög redan tidigt på säsongen. Foto författaren, 1 juni 2008.

Part of the survey area. After cessation of grazing the vegetation grows tall already in early summer. Photo by the author, 1 June 2008.

Samtliga inventeringar utfördes mellan kl 06 och 09.30 och resultaten speglar alltså den fågelfauna, som kan ses vid den tiden på dygnet.

Jag har använt mig av samma uppdelning i jordbruks-, skogs- och övriga arter som används inom de europeiska indikatorerna för "Vanliga jordbruksfåglar", "Vanliga skogsfåglar" och "Övriga vanliga fåglar" (se Lindström m.fl. 2012). Gräsytornas storlek vid varje punkt har mätts baserat på hur jag kunnat överblicka dem vid inventeringarna och säkert kunnat bestämma iakttagna jordbruksfåglar. I de flesta fall har det funnits naturliga gränser med trädridåer, skogskanter och liknande, vilket alltså innebär den totala gräsytan runt en inventeringspunkt. Uppmätningen har skett med hjälp av mätverktyget i länstyrelsernas länskartprogram (http://gis.lst.se/ lanskartor/htm/viewer.asp).

Statistiska beräkningar, dvs. regressionsanalyser, two-tailed t-tester och Mann-Whitney U-tester (när det varit få observationer), har gjorts med hjälp av programmet Minitab. Jag redovisar medelvärden \pm se (standard error) i text och tabeller, om inte annat anges.

\section{Undersökningsområde}

Det militära området, som räkningarna genomfördes på, är cirka $4 \mathrm{~km}^{2}$. Av detta är cirka $1,5 \mathrm{~km}^{2}$ gräsytor varav cirka 256 ha åker. Punktinventeringarnas gräsyta har varit en väsentligen mindre del, cirka 583 ha. Gräsytan var i medeltal per punkt $29,2 \pm 17$ ha $(\mathrm{n}=20)$.

Av områdets 20 punkter ligger bara 13 punkter inom det område som betades av kor. Trots detta gör jag i den här studien jämförelser baserat på hela området. Innan korna försvann var gräshöjden på aktuella punkter i början av maj cirka $10 \mathrm{~cm}$ och denna gräshöjd bestod över häckningssäsongen med grästuvor här och där. Efter betesdriftens upphörande var gräshöjden 20-30 cm redan i början av maj och oftast runt $50 \mathrm{~cm}$ eller mer senare i juli (Figur 1). Jag upplevde också en påtaglig förändring på så sätt att gräset blev mycket tätare och var mer som en tjock matta efter att betesdriften upphörde.

Efter att betesdriften upphört fanns det vid punkterna 5-9 en gräsmark som skördades som vall någon gång under sommaren, ibland före och ibland efter juli-inventeringen, medan övriga punkter med gräsmark lämnades orörda. Vid två punkter bedrevs aktivt jordbruk. Upplöjning av marken 
Tabell 1. Medelantalet arter per inventeringsperiod (medelvärde \pm se). Skillnaderna har jämförts med two-tailed t-test (t) eller Mann-Whitneys U-test (W).

Average number of species in relation to investigation period. Two-tailed t-test (t) or Mann-Whitney U-test (W) have been used.

\begin{tabular}{llll}
\hline Period & Medelantal arter & Medelantal arter & Skillnad \\
Period & Mean no. species & Mean no. species & Difference \\
& $1987-2006$ & $2007 / 2008-2012$ & \\
\hline Maj May & $42,9 \pm 0,5(\mathrm{n}=20)$ & $44,7 \pm 1,3(\mathrm{n}=6)$ & $\mathrm{t}=1,28 ; \mathrm{p}=0,25$ \\
Juni June & $47,8 \pm 0,85(\mathrm{n}=8)$ & $48,0 \pm 1,5(\mathrm{n}=5)$ & $\mathrm{W}=53,5 ; \mathrm{p}=0,77$ \\
Juli July & $44,7 \pm 1,3(\mathrm{n}=6)$ & $45,6 \pm 1,5(\mathrm{n}=5)$ & $\mathrm{W}=35 ; \mathrm{p}=0,93$ \\
\hline
\end{tabular}

skedde vissa år, anläggning av vall och odling av stråsäd har skett i omgångar vid båda dessa punkter under hela inventeringsperioden 1987-2012. Huvudsakligen har dock dessa ytor varit antingen vall eller stråsäd, men jag har inte gjort några särskilda noteringar om detta.

Några andra påtagliga förändringar i områdets miljö har inte noterats, förutom ett vägbygge som berört punkt 19. Detta förefaller inte ha påverkat antalet fåglar negativt (regressionstest; $r^{2}=0$; $\mathrm{p}=0,78 ; \mathrm{n}=26$ ). Vid punkt nummer 20 har varken kor eller får betat under någon period, och här har gräset hela tiden varit relativt tätt och högt.

\section{Resultat}

Antalet observerade arter per år varierade mellan 41 och 50 arter vid maj-inventeringen och var i medeltal 43,3 $\pm 2,5$ ( $n=26$ ). Någon skillnad $\mathrm{i}$ antalet arter före och efter betesdriftens upphörande kunde inte noteras (Tabell 1).

Antalet sedda fåglar vid de olika inventeringsperioderna framgår av Tabell 2. Totalt har antalet fåglar minskat vid juni-inventeringarna medan gruppen "Övriga arter" har ökat i antal. Ingen grupp har minskat vid inventeringen i juli. De arter som häckar inom de öppna gräsmarkerna ("Jordbruksarter") har gått ned kraftigt i antal. För gruppen "Övriga arter" noteras en liten ökning vid inventeringen $i$ juni.

"Jordbruksarterna" stod för hela minskningen (regressionstest; $r^{2}=-0,35 ; p=0,001$ ), medan "Skogsarterna" (regressionstest; $\mathrm{r}^{2}=0,03 ; \mathrm{p}=0,19$ ) och "Övriga arter" inte minskat $\mathrm{i}$ individantal (regressionstest; $\mathrm{r}^{2}=0,08 ; \mathrm{p}=0,085$ ).

Tabell 2. Medelantalet fåglar per år före och efter betesdriftens upphörande vid respektive inventering. Jämförelsen gäller alla arter (Totalt), Jordbruksarter och Övriga arter (Skogsarter redovisas inte).

Average number of birds per year reported separately for the period before grazing ceased (1987-2006; Before) and the period when grazing had ceased (2007-2012; After). The comparison includes the total number of observed birds (Total), as well as Farmland birds and Other birds shown separately (Woodland birds are not included).

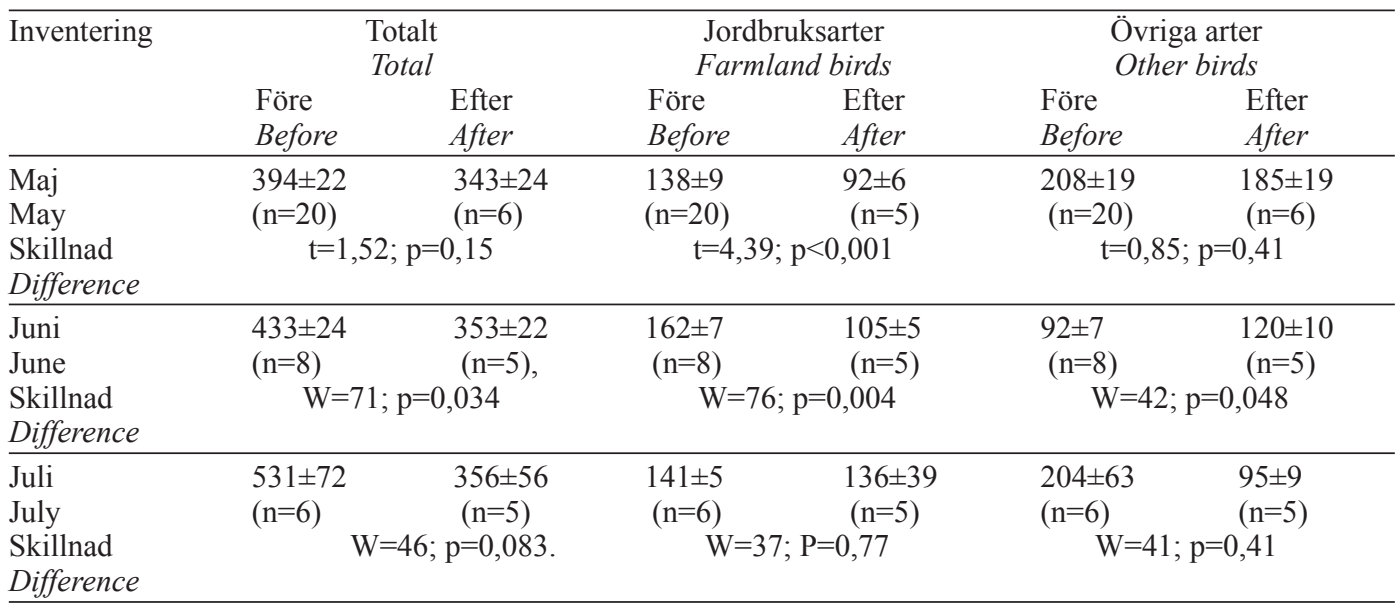


Tabell 3. Antal tornfalk Falco tinnunculus (medelantal/år \pm se) under och efter betningsperioden.

Number of Kestrels Falco tinnunculus (mean/year \pm se) during and after the grazing period.

\begin{tabular}{llll}
\hline & $\begin{array}{l}\text { Under } \\
\text { During }\end{array}$ & $\begin{array}{l}\text { Efter } \\
\text { After }\end{array}$ & $\begin{array}{l}\text { Skillnad } \\
\text { Statistical test }\end{array}$ \\
\hline Maj & $2,60 \pm 0,39$ & $3,83 \pm 0,79$ & $\mathrm{t}=1,40 ; \mathrm{p}=0,21$ \\
Juni & $1,63 \pm 0,57$ & $1,8 \pm 0,74$ & $\mathrm{~W}=55 ; \mathrm{p}=0,94$ \\
Juli & $3,33 \pm 1,63$ & $3,8 \pm 1,62$ & $\mathrm{~W}=34 ; \mathrm{p}=0,78$ \\
\hline
\end{tabular}

Tabell 4. Antal tofsvipa Vanellus vanellus (medelantal/år \pm se) under och efter betningsperioden.

Number of Lapwings Vanellus vanellus mean/ year \pm se) during and after the grazing period.

\begin{tabular}{llll}
\hline & $\begin{array}{l}\text { Under } \\
\text { During }\end{array}$ & $\begin{array}{l}\text { Efter } \\
\text { After }\end{array}$ & $\begin{array}{l}\text { Statistisk test } \\
\text { Statistical test }\end{array}$ \\
\hline Maj & $18,8 \pm 1,4$ & $6,2 \pm 1,3$ & $\mathrm{t}=6,61 ; \mathrm{p}<0,001$ \\
Juni & $18,4 \pm 2,3$ & $6,8 \pm 1,3$ & $\mathrm{~W}=76 ; \mathrm{p}=0,004$ \\
Juli & $23,8 \pm 8,2$ & $5,6 \pm 3,3$ & $\mathrm{~W}=43 ; \mathrm{p}=0,23$ \\
\hline
\end{tabular}

Tabell 5. Antal sånglärka Alauda arvensis (medelantal/år \pm se) under och efter betningsperioden.

Number of Skylarks Alauda arvensis (mean/year \pm se) during and after the grazing period.

\begin{tabular}{llll}
\hline & $\begin{array}{l}\text { Under } \\
\text { During }\end{array}$ & $\begin{array}{l}\text { Efter } \\
\text { After }\end{array}$ & $\begin{array}{l}\text { Statistisk test } \\
\text { Statistical test }\end{array}$ \\
\hline Maj & $54,5 \pm 3,8$ & $40,2 \pm 2,3$ & $\mathrm{t}=3,24 ; \mathrm{p}=0,004$ \\
Juni & $73,1 \pm 6,0$ & $39,4 \pm 1,5$ & $\mathrm{~W}=75 ; \mathrm{p}=0,007$ \\
Juli & $65,3 \pm 2,4$ & $34,0 \pm 3,2$ & $\mathrm{~W}=51 ; \mathrm{p}=0,008$ \\
\hline
\end{tabular}

Tabell 6. Antal buskskvätta Saxicola rubetra (medelantal/år \pm se) under och efter betningsperioden.

Number of Whinchats Saxicola rubetra (mean/ year \pm se) during and after the grazing period.

\begin{tabular}{llll}
\hline & $\begin{array}{l}\text { Under } \\
\text { During }\end{array}$ & $\begin{array}{l}\text { Efter } \\
\text { After }\end{array}$ & $\begin{array}{l}\text { Statistisk test } \\
\text { Statistical test }\end{array}$ \\
\hline Maj & $2,6 \pm 0,6$ & $5,5 \pm 0,7$ & $\mathrm{t}=3,30 ; \mathrm{p}=0,006$ \\
Juni & $6,4 \pm 0,9$ & $11,0 \pm 1,7$ & $\mathrm{~W}=41,5 ; \mathrm{p}=0,04$ \\
Juli & $4,2 \pm 1,2$ & $13,8 \pm 3,5$ & $\mathrm{~W}=26 ; \mathrm{p}=0,08$ \\
\hline
\end{tabular}

Tabell 7. Antal Ängspiplärka Anthus pratensis (medelantal/år \pm se) under och efter betningsperioden.

Number of Meadow Pipits Anthus pratensis (mean/ year \pm se) during and after the grazing period.

\begin{tabular}{llll}
\hline & $\begin{array}{l}\text { Under } \\
\text { During }\end{array}$ & $\begin{array}{l}\text { Efter } \\
\text { After }\end{array}$ & $\begin{array}{l}\text { Statistisk test } \\
\text { Statistical test }\end{array}$ \\
\hline Maj & $18,9 \pm 7,1$ & $8,0 \pm 1,1$ & $\mathrm{t}=1,53 ; \mathrm{p}=0,14$ \\
Juni & $3,5 \pm 0,93$ & $6,0 \pm 0,6$ & $\mathrm{~W}=41,5 ; \mathrm{p}=0,04$ \\
Juli & $6,33 \pm 1,36$ & $8,20 \pm 2,06$ & $\mathrm{~W}=33,5 ; \mathrm{p}=0,72$ \\
\hline
\end{tabular}

Tabell 8. Antal stare Sturnus vulgaris (medelantal/ år \pm se) under och efter betningsperioden.

Number of Starlings Sturnus vulgaris (mean/year \pm se) during and after the grazing period.

\begin{tabular}{llll}
\hline & $\begin{array}{l}\text { Under } \\
\text { During }\end{array}$ & $\begin{array}{l}\text { Efter } \\
\text { After }\end{array}$ & $\begin{array}{l}\text { Statistisk test } \\
\text { Statistical test }\end{array}$ \\
\hline Maj & $31,1 \pm 3,8$ & $22,7 \pm 5,7$ & $\mathrm{t}=1,27 ; \mathrm{p}=0,23$ \\
Juni & $41 \pm 3,8$ & $25,8 \pm 3,1$ & $\mathrm{~W}=72 ; \mathrm{p}=0,023$ \\
Juli & $20,5 \pm 9,5$ & $48,8 \pm 38,1$ & $\mathrm{~W}=38 ; \mathrm{p}=0,78$ \\
\hline
\end{tabular}

Tabell 9. Antal hämpling Carduelis cannabina (medelantal/år \pm se) under och efter betningsperioden.

Number of Linnet Carduelis cannabina (mean/ year \pm se) during and after the grazing period.

\begin{tabular}{llll}
\hline & $\begin{array}{l}\text { Under } \\
\text { During }\end{array}$ & $\begin{array}{l}\text { Efter } \\
\text { After }\end{array}$ & $\begin{array}{l}\text { Statistisk test } \\
\text { Statistical test }\end{array}$ \\
\hline Maj & $2,35 \pm 0,64$ & $0,67 \pm 0,33$ & $\mathrm{t}=2,33 ; \mathrm{p}=0,029$ \\
Juni & $1,67 \pm 0,71$ & 0 & \\
Juli & $1,67 \pm 0,71$ & $0,8 \pm 0,58$ & $\mathrm{~W}=42 ; \mathrm{p}=0,29$ \\
\hline
\end{tabular}

Tabell 10. Antal enkelbeckasinen Gallinago gallinago (medelantal/år \pm se) under och efter betningsperioden. Number of Common Snipes Gallinago gallinago (mean/year \pm se) during and after the grazing period.

\begin{tabular}{llll}
\hline & $\begin{array}{l}\text { Under } \\
\text { During }\end{array}$ & $\begin{array}{l}\text { Efter } \\
\text { After }\end{array}$ & $\begin{array}{l}\text { Statistisk test } \\
\text { Statistical test }\end{array}$ \\
\hline Maj & $1,5 \pm 0,33$ & $0,33 \pm 0,21$ & $\mathrm{t}=2,94 ; \mathrm{p}=0,007$ \\
Juni & $0,63 \pm 0,26$ & 0 & \\
Juli & $0,17 \pm 0,17$ & 0 & \\
\hline
\end{tabular}

Tabell 11. Antal gräshoppsångare Locustella naevia (medelantal/år \pm se) under och efter betningsperioden. Number of Grasshopper Warblers Locustella naevia (mean/year \pm se) during and after the grazing period.

\begin{tabular}{llll}
\hline & $\begin{array}{l}\text { Under } \\
\text { During }\end{array}$ & $\begin{array}{l}\text { Efter } \\
\text { After }\end{array}$ & $\begin{array}{l}\text { Statistisk test } \\
\text { Statistical test }\end{array}$ \\
\hline Maj & 0 & 0 & \\
Juni & $0,125 \pm 0,125$ & $1,4 \pm 0,93$ & $\mathrm{~W}=46 ; \mathrm{p}=0,09$ \\
Juli & $0(\mathrm{n}=6)$ & $1,6 \pm 0,68$ & \\
\hline
\end{tabular}

Tabell 12. Antal stenskvätta Oenanthe oenanthe medelantal/år \pm se) under och efter betningsperioden. Number of Wheatears Oenanthe oenanthe mean/ year \pm se) during and after the grazing period.

\begin{tabular}{llll}
\hline & $\begin{array}{l}\text { Under } \\
\text { During }\end{array}$ & $\begin{array}{l}\text { Efter } \\
\text { After }\end{array}$ & $\begin{array}{l}\text { Statistisk test } \\
\text { Statistical test }\end{array}$ \\
\hline Maj & $0,8 \pm 0,22$ & $1,5 \pm 0,72$ & $\mathrm{t}=0,93 ; \mathrm{p}=0,39$ \\
Juni & $0,125 \pm 0,125$ & $0,4 \pm 0,4$ & $\mathrm{~W}=54 ; \mathrm{p}=0,73$ \\
Juli & $0,17 \pm 0,17$ & 0 & \\
\hline
\end{tabular}




\section{Tornfalk Falco tinnunculus}

Arten har inte genomgått några större antalsförändringar över tiden (regressionstest; $r^{2}=0, p=0,52$, $n=26$; Tabell 3). I området finns några holkar uppsatta för att underlätta för tornfalkens häckning och innan den första holken kom upp fanns, såvitt jag känner till, endast en frihäckning.

\section{Kornknarr Crex crex}

Även kornknarr, som är en mer ovanlig jordbruksanknuten art, har noterats i området på senare tid (1 ex 2009, 2 ex 2010 och 1 ex 2012).

\section{Tofsvipa Vanellus vanellus}

För hela undersökningsperioden har tofsvipan minskat i området (regressionstest; $\mathrm{r}^{2}=-0,18$; $\mathrm{p}=0,019 ; \mathrm{n}=26$ ). För åren 1987-2006 fanns ingen minskning (regressionstest; $r^{2}=0, p=0,65 ; n=19$ ). Skillnaden mellan före och efter betesdriftens upphörande framgår av Tabell 4.

\section{Sånglärka Alauda arvensis}

I undersökningsområdet har sånglärkan minskat (regressionstest; $\mathrm{r}^{2}=-0,52 ; \mathrm{p}<0,001 ; \mathrm{n}=26$ ) vid maj-inventeringarna. Dock hade det redan innan betesdriften upphörde skett en kraftig nedgång i sånglärkans bestånd (regressionstest; $r^{2}=-0,53$; $\mathrm{p}<0,001 ; \mathrm{n}=19$ ). Trots det är nedgången $\mathrm{i}$ antal påtaglig från perioden med betesdrift till perioden då betesdriften upphört (Tabell 5).

\section{Buskskvätta Saxicola rubetra}

Arten visar sig, till skillnad från övriga jordbruksarter, ha ökat vid alla tre inventeringstillfällena även om skillnaden vid juni-inventeringen inte är statistiskt säkerställd (Tabell 6).

\section{Ängspiplärka Anthus pratensis}

Ängspiplärkan har inte antalsmässigt genomgått några förändringar över hela inventeringsperioden (regressionstest; $\mathrm{r}^{2}=0, \mathrm{p}=0,35, \mathrm{n}=26$ ). Även om maj-inventeringarna visar att beståndet mer än halverats, så är denna förändring inte statistiskt säkerställd. Juni-inventeringarna ger dock vid handen att arten ökat kraftigt och denna förändring är statistiskt säkerställd (Tabell 7).

\section{Stare Sturnus vulgaris}

Några förändringar i antal vid maj- och juli-inventeringarna kunde inte noteras, medan juni-inventeringen visar en minskning efter betesdriftens upphörande (Tabell 8).

\section{Hämpling Carduelis cannabina}

Hämplingen är normalt sparsamt förekommande och har knappast blivit vanligare i samband med att betesdriften upphörde (Tabell 9). Arten har minskat sett över hela perioden (regressionstest; $r^{2}=-0,29$; $\mathrm{p}=0,003 ; \mathrm{n}=26)$, men denna minskning hade inletts redan innan betesdriften upphörde (regressiontstest; $\left.{ }^{\mathrm{r}} 2=-0,27 ; p=0,011 ; n=19\right)$. Numera visar maj och juli-inventeringarna låga antal, medan arten helt försvunnit under juni -inventeringarna.

För gruppen övriga arter är bilden mer splittrad och jag har valt tre arter ur denna grupp. Dessa tre arter lever i ett öppet landskap där igenväxning kan tänkas ha betydelse.

\section{Enkelbeckasin Gallinago gallinago}

För hela perioden 1986-2012 har det inte skett några förändringar under maj-inventeringen (regressionstest; $\left.r^{2}=0 ; p=0,36 ; n=26\right)$. Efter att betesdriften upphört försvinner enkelbeckasinen helt under sommaren (dvs. juni- och juli-inventeringarna) och maj-inventeringarna uppvisar också en minskning som är statistiskt verifierbar (Tabell 10).

\section{Gräshoppsångaren Locustella naevia}

Arten har påträffats i låga antal (i medeltal 1,4-1,6 per år) under juni- och juli-inventeringarna under perioden då betesdriften upphört (Tabell 11). Under betesperioden sågs arten bara en gång.

\section{Stenskvätta Oenanthe oenanthe}

Över hela perioden noterades inga förändringar $\mathrm{i}$ antalet stenskvättor (regressionstest; $\mathrm{r}^{2}=0,02$; $\mathrm{p}=0,24 ; \mathrm{n}=26$ ). Däremot gjordes inga observationer alls under juli-inventeringarna efter att betesdriften upphört 2007-2012 (Tabell 12).

\section{Diskussion}

Materialet är inte särskilt stort, men för jordbruksarterna verkar förändringarna ha varit så stora att de ändå slår igenom i materialet. Betesdriftens upphörande innebar för jordbruksarterna att tre arter ökade medan fyra arter minskade och en art uppträdde i oförändrat antal. Jämfört med hela Sverige, kan man notera att sånglärkan, tofsvipan och hämplingen har minskat både $\mathrm{i}$ riket som helhet och $\mathrm{i}$ undersökningsområdet. Staren och ängspiplärkan intar båda en särställning så tillvida att, om vi antar att juni-inventeringen representerar den häckande populationen i området, har dessa arter också minskat. För båda arterna är vårsträcket $\mathrm{i}$ full gång vid maj-inventeringen och vid juli-inventeringen är det 
åtminstone för staren så att större ungfågelflockar drar omkring i området. Buskskvättan har däremot minskat i riket (Lindström m.fl. 2012) medan den har ökat i antal i studieområdet. Att buskskvättan har ökat i mitt område beror sannolikt på att den både getts möjlighet att gömma bon och hitta mer föda i det högre och tätare gräset (Glutz von Blotzheim $\mathrm{m}$. fl 1988).

Tofsvipans minskning i området kan sannolikt helt tillskrivas betesdriftens upphörande eftersom beståndet var stabilt under perioden med betesdrift. I högt gräs har de inte samma möjlighet att anlägga bo och söka föda till sig själva och ungarna då det sannolikt blir mer svåråtkomligt (Glutz von Blotzheim m.fl. 1975). Vid juli-inventeringen finns ingen minskning noterad för tofsvipan. De tofsvipor som sågs vid juli-inventeringen har jag betraktat som flyttande och alltså inte en del av det häckande beståndet, men inventeringsmetoden anger att allt skall räknas. Om jag bortser från individer som uppvisat beteende typiskt för flyttande/rastande tofsvipor skulle medeltalet vid juli-inventeringen vara $2,6 \pm 2,36$, vilket skulle innebära en minskning även under sensommaren ( $W=38 ; p=0,037)$. I medeltal fanns det $10 \pm 1,52$ tofsvipor per år på de 14 punkter med möjlig häckningsyta. På dessa punkter var gräsytan i medeltal $36,9 \pm 3,5$ ha. Ju större gräsyta runt en punkt desto längre hade det funnits tofsvipor vid maj-inventeringarna (regressionstest; $\mathrm{r} 2=0,3 ; \mathrm{p}=0,007 ; \mathrm{n}=20$ ). De ytor där tofsvipor funnits längst är de som i sin tur gränsat till ännu större gräsytor. Innan betesdriften upphörde var beståndets storlek i medeltal 32 exemplar $/ \mathrm{km}^{2}$, vilket kan jämföras med $100 \mathrm{par} / \mathrm{km}^{2}$ på betade strandängar och 0,3 och 3,4 par $/ \mathrm{km}^{2}$ på jordbruksmark (Ottosson m. fl. 2012).

När det gäller tornfalken har den inte ökat, även om man får den känslan när man besöker området.

För ängspiplärkan gäller att det inte finns någon statistisk skillnad mellan före och efter betesdriftens upphörande. Men ökningen vid juni-inventeringen verkar avspegla att arten faktiskt har ökat i området. Att maj-inventeringarna inte uppvisar en ökning kan avspegla att det under denna tid är gott om nordsträckande ängspiplärkor. Tätheten var 11,3 exemplar $/ \mathrm{km}^{2}$ efter betesdriftens upphörande, vilket kan jämföras med ett medelvärde för hela Sverige på 3-7 par $/ \mathrm{km}^{2}$ (Ottosson m. fl 2012).

Sånglärkan har setts vid 19 av 20 punkter med $3,46 \pm 0,42$ exemplar/punkt före och 2,40 $\pm 0,40$ efter betesdriftens upphörande. Något samband fanns inte mellan gräshöjd och antalet par per punkt $\mathrm{i}$ medeltal (regressionstest; $r^{2}=0 ; p=0,54 ; n=20$ ). Donald (2004) menar att gräsets täthet är viktigare än själva gräshöjden. Och generellt sett hävdar Donald (2004) att gräsmarker inte är den biotop som hyser den tätaste sånglärkeförekomsten. I takt med att sånglärkan minskat har antalet punkter där arten noterats minskat $\left(r^{2}=-0,33 ; p=0,001 ; n=26\right)$. Arten har setts fler säsonger per punkt ju större gräsytorna varit (regressionstest; $\mathrm{r}^{2}=0,63 ; \mathrm{p}<0,001 ; \mathrm{n}=20$ ), vilket torde innebära att de mest ogynnsamma biotoperna, dvs. de minsta gräsytorna, har övergetts först. Antalet exemplar $/ \mathrm{km}^{2}$ varierar enligt Donald (2004) kraftigt och han anger en täthet från trakten av Baikalsjön på 113 exemplar $/ \mathrm{km}^{2}$ och en högsta täthet från Storbritannien på $36 \mathrm{par} / \mathrm{km}^{2}$. I Sverige ligger populationstätheten i gynnsamma områden på 2-60 par $/ \mathrm{km}^{2}$ men mer typiskt är $10-30 \mathrm{par} / \mathrm{km}^{2}$ och på alvarmark, en biotop som mer liknar min inventeringsyta, på $77 \mathrm{par} / \mathrm{km}^{2}$ (Ottosson m.fl. 2012). I mitt studieområde var tätheten före betesdriftens upphörande 118 exemplar $/ \mathrm{km}^{2}$ och efter betet upphörde 82 exemplar $/ \mathrm{km}^{2}$. Således ligger sånglärkans populationsstorlek fortfarande på en mycket hög nivå trots betesdriftens upphörande.

Stenskvättan har minskat i Sverige (Lindström m.fl. 2012), men någon förändring har inte noterats i mitt undersökningsområde. Tätheten var 2,6 exemplar $/ \mathrm{km}^{2}$ i mitt studieområde medan Ottosson m.fl. (2012) anger $10-35 \mathrm{par} / \mathrm{km}^{2}$ som typiskt för betesmarker i södra Sverige. Arten har således en sparsam förekomst i mitt studieområde. En orsak till varför arten inte verkar ha påverkats av att gräshöjden ökat i studieområdet kan vara att den främst häckar i stenrösen. Dock födosöker stenskvättor gärna på mark med ganska kort gräs (Glutz von Blotzheim \& Bauer 1988), vilket kan förklara varför arten inte noterats under juli-inventeringarna

Gräshoppsångaren har ökat i området men minskat i Sverige som helhet (Lindström m.fl. 2012). Att arten ökat borde rimligtvis bero på att gräset tillåtits växa fritt och att man på något ställe kan skönja nyetablering av små buskage. Det är sannolikt att arten kommer att öka ytterligare allteftersom buskagen sprider sig. Tätheten i mitt undersökningsområde var 2,74 exemplar $/ \mathrm{km}^{2}$, medan den typiska tätheten för Sverige uppskattats till 3-6 $\operatorname{par} / \mathrm{km}^{2}$ (Ottosson m.fl. 2012).

Enkelbeckasinen visade sig minska drastiskt i mitt studieområde, vilket följer trenden för arten i riket som helhet (Lindström m.fl. 2012). Att koppla minskningen $\mathrm{i}$ inventeringsområdet till igenväxning kanske inte är helt självklart. Glutz m.fl (1977) anger att arten föredrar gräsmarker, dock inte med för högt gräs under häckningstid, och att dessa gräsmarker dessutom bör vara fuktiga. Det senare kravet tillfredsställs av de bäckar som rinner 
genom mitt studieområde. I princip alla observationer av enkelbeckasin har gjorts vid punkter i nära anslutning till de små bäckarna som rinner genom området. Före betesdriftens upphörande var tätheten 2,56 exemplar $/ \mathrm{km}^{2}$ jämfört med en typisk täthet på 1-3 par $/ \mathrm{km}^{2}$ för Sverige som helhet (Ottosson m.fl. 2012).

\section{Slutsatser}

Kor, och i en liten del även får, har uppenbarligen stor betydelse för fågelfaunans sammansättning och numerär. Av beskrivna jordbruksarter har två ökat, fyra minskat och två noterat oförändrat status. Totalt har antalet exemplar dramatiskt minskat

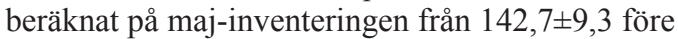
till 92,5 $\pm 5,7$ exemplar efter betet upphört (twotailed t-test; $\mathrm{t}=4,60 ; \mathrm{p}<0,001, \mathrm{n}=26$ ). Hur området attraherar rastande fåglar går inte att utläsa av den undersökningen men rimligtvis borde igenväxning leda till att möjligheter att finna föda vid vattenansamlingar och andra öppna ytor minska och därmed antalet fåglar. Arterna i den här sammanställningen är helt beroende av hur militära myndigheter vill sköta området i framtiden, med eller utan boskap.

\section{Tack}

Per-Olof Brander och Anna-Klara Brander tackas för granskning av ett första manusutkast.

\section{Referenser}

Donald, P.F. 2004. The Skylark. T \& A D Poyser. London. Glutz von Blotzheim, U.N., Bauer, K.M. \& Bezzel, E. 1975. Handbuch der Vögel Mitteleuropas. Band 6. Akademische Verlagsgesellschaft. Wiesbaden.

Glutz von Blotzheim, U.N. \& Bauer, K. 1988. Handbuch der Vögel Mitteleuropas. Band 11/1. AULA-Verlag Wiesbaden.

Lindström, Å., Green, M. \& Ottvall, R. 2012. Övervakning av fåglarnas populationsutveckling. Årsrapport för 2011. Lund.

Ottosson, U., Ottvall, R., Elmberg, J., Green, M., Gustafsson, R., Haas, F., Holmkvist, N., Lindström, Å., Nilsson, L., Svensson, M. Svensson, S. \& Tjernberg, M. 2012. Fåglarna i Sverige - antal och förekomst. SOF, Halmstad.

Svensson, S. 1988. Svenska Häckfågeltaxeringen. Punkttaxeringsmetoden Resultatprotokoll.

Wretenberg, J. 2006. The Decline of Farmland Birds in Sweden. Doctoral Thesis. Acta Universitatis Agriculturae Sueciae 2006: 113

\section{Summary}

In a military training area with open grassland and woodlots, I have counted birds since 1987, using the standardized method for point census implemented by the Swedish Bird Survey (see Lindström et al. 2012). Every bird seen or heard during 5 minutes at 20 points at any distance from the point was censused. Points were located 600-4000 $\mathrm{m}$ apart. The open parts of my study area were mainly pasture grazed by ca. 500 cattle until 2006 . Between 2007 and 2012, there have been no cattle grazing in the study area (Figure 1). Each year, census visits have been conducted 1 May in 19872012, 1 June in 1987-1994 and 2008-2012, and 1 July in 1989-1995 and 2008-2012. The field work has been carried out between $06.00 \mathrm{~h}$ and $09.30 \mathrm{~h}$ at each visit. I have classified the bird species into three habitat-based groups: Forest, Farmland and Other bird species according to Lindström et al. (2012). The estimation of Farmland birds $/ \mathrm{km}^{2}$ is based on the area of grass coverage around each census point, which on average has been $29,2 \pm 3,8$ ha $(n=20)$, and a total area of 583 ha.

The total number of bird species was on average $43.3 \pm 2.5$ species/year ( $n=26$; range $41-50$ species/year), and it did not change between 1987 and 2012. There was no difference in total number of bird species during the period of cattle grazing as compared with the period when grazing had ceased (Table 1).

The total number of bird species has decreased during the June census period, while the group 'Other species' has increased (Table 2). No group has decreased during the July census period. However, the number of 'Farmland' bird species has decreased in general (Table 2).

There have been no changes in the number of Kestrels Falco tinnunculus over the study period (Table 3).

Between 1987 and 2012, the Lapwing Vanellus vanellus has decreased in the study area (regression test; $\mathrm{r}^{2}=-0.18 ; \mathrm{p}=0.019 ; \mathrm{n}=26$ ), and this mirrors the pattern for the whole of Sweden (Lindström et al. 2012). However, there was no decrease during the period 1987-2006 (regression test; $\mathrm{r}^{2}=0 ; \mathrm{p}=0.65$; $\mathrm{n}=19$; Table 4), implying that the decrease is related to the ceased cattle grazing. In suitable breeding areas, i.e., grassland, Lapwings occurred in on average $7 \pm 6.65$ (sd) years out of the 26 years. There was a connection between the number of years when Lapwings had been seen at least once per year at a point and the size of the grass area surrounding the point $\left(\mathrm{r}^{2}=0.3 ; \mathrm{p}=0.007 ; \mathrm{n}=20\right)$. During 
the grazing period the population was 32 individuals $/ \mathrm{km}^{2}$ compared to $0.3-3.4$ pairs $/ \mathrm{km}^{2}$ in farmlands in general in Sweden (Ottosson et al. 2012).

The Skylark Alauda arvensis has decreased (regression test; $\mathrm{r}^{2}=-0.52 ; \mathrm{p}<0.001 ; \mathrm{n}=26$ ) over the whole period in the May census, which is in accordance with the general pattern for Sweden (Lindström et al. 2012). Moreover, the number of Skylarks also decreased in my study area between the period when grazing occurred as compared with the period without grazing (Table 5). No relationship was found between grass height and the number of Skylarks (regression test; $r^{2}=0 ; p=0.54$; $\mathrm{n}=20$ ). Over the 26 year period, the number of count points where Skylarks have been observed at least once per year has decreased (regression test; $\mathrm{r}^{2}=-0.33 ; \mathrm{p}=0.001 ; \mathrm{n}=26$ ). There was also a relationship showing that the larger the grass area around a census point the more years Skylarks have been observed at this point $\left(\mathrm{r}^{2}=0.63 ; \mathrm{p}<0.001\right.$; $\mathrm{n}=20$ ), which implies that the smallest grass areas are abandoned first. In Sweden, the typical density of Skylarks is $10-30$ pairs $/ \mathrm{km}^{2}$ (Ottosson et al. 2012). In my study area, I found 118 individuals/ $\mathrm{km}^{2}$ during the grazing period and 82 individuals/ $\mathrm{km}^{2}$ after the grazing had ceased.

The Whinchat has decreased in Sweden (Lindström et al. 2012) but increased in my study area (Table 6), which probably depends on better nest coverage and feeding possibilities in the taller, denser grass (Glutz von Blotzheim et al. 1988) after the grazing ended.

The number of Meadow Pipits Anthus pratensis has not changed in the May census period between 1987 and 2012 (regression test; $r^{2}=0$; $\mathrm{p}=0.35 ; \mathrm{n}=26$ ). During the June census period there has even been an increase (Table 7), and this census period is probably more representative of the actual breeding population. The density of the Meadow Pipit was 11.3 individuals $/ \mathrm{km}^{2}$ during the non-grazing period, which can be compared to 3-7 pairs $/ \mathrm{km}^{2}$ for the whole country of Sweden (Ottosson et. al (2012).

The number of Starlings Sturnus vulgaris has not changed between 1987 and 2012 (Table 8). However, if using only the June census period as an estimate of the local breeding population, then the Starling has decreased in my study area (Table 8).

The Linnet Carduelis cannabina has decreased over the whole study period (regression test; $r^{2}=-0.29 ; p=0.003 ; n=26$; Table 9), which is similar to the general trend in Sweden (Lindström et al. 2012). However, this decrease began before the cattle grazing ceased (regression test; $\mathrm{r}^{2}=-0.27$; $\mathrm{p}=0.011 ; \mathrm{n}=19$ ).

The number of Common Snipes Gallinago gallinago did not show a significant change over the 26 year period (regression test; $\mathrm{r}^{2}=0 ; \mathrm{p}=0.36 ; \mathrm{n}=26$ ). However, when comparing the density in the grazing period with the density in the period after grazing had ceased, the Snipe decreased significantly in numbers (Table 10), which may depend on the taller grass in the latter period (cf. Glutz et al 1977). The Common Snipe has decreased in my study area and the same is true for the whole of Sweden (Lindström et al. 2012). During 1987-2006 the population density was 2.56 individuals $/ \mathrm{km}^{2} \mathrm{com}$ pared to 1-3 pairs $/ \mathrm{km}^{2}$ for Sweden as a whole (Ottosson et al. 2012).

The Grasshopper Warbler Locustella naevia has been a new species to the study area during the last 5 years, and it has only been observed in the June and July census periods (Table 11). This is in contrast to the generally decreasing trend in Sweden (Lindström et al. 2012). Its recent increase in the study area probably depends on the taller, thicker grass and recent establishment of small bushes on the grasslands after the grazing ceased. The population density was 2.74 individuals $/ \mathrm{km}^{2}$ in my study area, which is close to the density in suitable habitats in Sweden of 3-6 pairs $/ \mathrm{km}^{2}$ (Ottosson et al. 2012).

In the whole of Sweden, the Wheatear has decreased (Lindström et al. 2012), but in my study area there has been no change in numbers 19872012 (Table 12). However, note that the population density was only 2.6 individuals $/ \mathrm{km}^{2}$ in the study area, compared with a typical density of 10-35 pairs $/ \mathrm{km}^{2}$ on pastures in southern Sweden (Ottosson et al. 2012).

Cattle are of great importance for the Farmland bird fauna, affecting both the species composition as well as the number of individuals/species. Two Farmland species have increased, four have decreased and in two species no changes have been recorded. The number of birds in the May counts have decreased from on average 142,7 49,3 individuals during the grazing period to $92,5 \pm 5,7$ individuals in the period when grazing had ceased (two-tailed t-test; $t=4,60 ; p<0,001, n=26$ ). The area and its Farmland birds are obviously depending upon how the military decide to manage the study area, with respect to cattle grazing. 